Article

\title{
Prediction of Fusion Hole Perforation Based on Arc Characteristics of Front Image in Backing Welding
}

\author{
Yu Cao ${ }^{1,2}$, Xiaofei Wang ${ }^{1,2}$, Xu Yan ${ }^{1,2}$, Chuanbao Jia ${ }^{1,2}$ and Jinqiang Gao ${ }^{2, *}$ \\ 1 MOE Key Lab for Liquid-Solid Structure Evolution and Materials Processing, Shandong University, \\ Jinan 250061, China; caoyu1506@163.com (Y.C.); welding09wang@163.com (X.W.); \\ hangangyanzi@163.com (X.Y.); jiachuanbao@sdu.edu.cn (C.J.) \\ 2 Institute of Materials Joining, Shandong University, Jinan 250061, China \\ * Correspondence: jqg@sdu.edu.cn
}

Received: 1 October 2020; Accepted: 19 October 2020; Published: 22 October 2020

check for updates

\begin{abstract}
In one-side welding with back-formation, the weld is penetrated after the fusion hole is perforated. Therefore, judging whether the fusion hole is perforated is very important to realize autocontrol of penetration in one-side welding with back-formation process. Previous researches mainly focused on the morphological characteristics of the molten pool and fusion hole to judge the weld penetration state. Sometimes it is difficult to obtain the morphological characteristics of the molten pool, keyhole and fusion hole and image processing is complex. In this paper, a visual detection system of fusion holes based on visual sensing is constructed to obtain the real-time fusion hole images in backing welding. It is found that the arc characteristics in the front images contain abundant information about the perforation of fusion hole. An image processing program is developed based on MATLAB software, and the arc characteristic parameters in front images are obtained. Taking the arc characteristic parameters as the input, obtaining the penalty function and the kernel function parameters through the cross validation and grid search method, a prediction model of fusion hole perforation based on the support vector machine is put forward. The accuracy for prediction samples is $88 \%$. By analyzing the misidentified samples, it is found that some of the newly perforated images are predicted as nonperforated ones, which has little influence on the penetration control of the weld.
\end{abstract}

Keywords: one-side welding with back-formation; fusion hole; visual sensing; prediction; arc characteristics

\section{Introduction}

The technology of one-side welding with back-formation is mainly applied to welding structures with limited space in the back. In order to ensure penetration, the technology generally requires a certain reserved gap for butt welding [1-3]. In the pressure vessel and pipeline industry, the technology of one-side welding with back-formation is a skill that welders must master. There always exists a fusion hole in the process of butt welding with reserved gap, which is a special phenomenon. The state that the bottom edge of the root under the fusion hole is melted is taken as perforation in this paper. The perforation of the fusion hole ensures the full melting of the root and the penetration of weld. Skilled welders can get the information to judge whether the weld is penetrated by observing the shape and size of the fusion hole in the welding process. Therefore, judging the perforation of the fusion hole in welding is of great significance to realize the welding automation of high-quality one-side welding with back-formation.

Welding is often accompanied by various physical phenomena [4,5], which contain numerous pieces of information closely related to the penetration state of the weld. Many sensing methods are 
adopted to obtain such information. Some researchers [6-8] utilized arc sound, welding voltage and current and other indirect signals obtained in the welding process to detect the welding state. Compared with the nonvisual signal sensing method, the visual signal sensing method has the advantages of high measuring accuracy, large amount of information and noncontact with the work piece, which is widely used in the shape detection of molten pool and keyhole [9,10]. Bae et al. [11] established a set of visual sensing systems for GMAW (gas metal arc welding) and extracted the shape of molten pool from the image of molten pool and surrounding area captured. They calculated the position of wire and molten pool center, realizing a good tracking of weld position with the maximum offset error of $1^{\circ}$, but the weld penetration was controlled according to the measured gap dimension and the visual detection of weld penetration wasn't realized in the experiment. Bacioiu et al. [12] adopted a neural network to learn the differences between good welds and defective welds and built the relationship between weld quality and morphological information of molten pool captured by HRD (high dynamic range) camera. Zhang et al. [13] obtained the backside images of molten pool and keyhole by using pulse triggered imaging method in K-TIG (keyhole tungsten inert gas) welding, and established the prediction model of the relationship between molten pool and keyhole and weld penetration. Zhang et al. $[14,15]$ built a set of CCD (charge-coupled device) double-sensor visual detection systems. They obtained the size and position information of the keyhole and backside molten pool, realizing the penetration control of stainless steel with the thickness of $11.5 \mathrm{~mm}$. Liu et al. [16-18] built a visual detection system for K-TIG welding, which realized the "one pulse, one hole" K-TIG welding process by using a square-wave pulse welding current. Through observing the K-TIG welding process of a stainless steel plate, they got the images of the keyhole in the backside of weld, and extracted the shape and position characteristic parameters of the keyhole. Luo et al. [19] established the relationship between welding parameters and unobservable keyhole geometry through a static neural network and obtained keyhole depth and inclination angle by the dynamic radial basis function neural network observer under varying welding parameters in PAW (plasma arc welding). Bardin et al. [20] built a closed-loop control system for LBW (laser beam welding). Through the focal control system, the laser beam could be kept focused over a wide range of welding parameters and full penetration was realized. With the keyhole image recognition system, the opening degree of the keyhole was analyzed and the energy inputted was adjusted to avoid burn-through and partial-penetration.

For work pieces with complex shapes, it is difficult to sense the weld penetration from the backside of weld, therefore judging the state of penetration based on the visual detection signals from the front is meaningful [21]. The image of the keyhole and molten pool reflects the penetration state of weld. Researchers have built various penetration prediction models based on machine learning [22]. Xia et al. [23] took the front image of the molten pool captured by HRD camera as the input, establishing a classification model of welding state through the CNN (convolutional neural network) method based on the residual network in K-TIG welding. The overall monitoring accuracy of partial-penetration, full-penetration and burn-through etc. reached 98\%. Liu et al. [24] used a deep-learning algorithm to predict the keyhole state in PAW, and built a perforation/penetration state prediction model for PAW. Taking the front molten pool images as the input of the model, the characteristic information of molten pool images was automatically extracted by $\mathrm{CNN}$, and the recognition rate of perforation state on the prediction data sets was more than $90 \%$. By using a BP (back propagation) neural network, $\mathrm{Gu}$ et al. [25] built a penetration state prediction model for K-TIG welding which took the geometric parameters of the molten pool and keyhole entrance as the input and the penetration state of back weld as the output. The result showed that the prediction accuracy of this model was more than $96 \%$, which realized a good prediction of penetration state. Similarly, by obtaining the characteristic information of keyhole and molten pool, the researchers have built a prediction model between the characteristic parameters and the penetration [26].

In one-side welding with back-formation, the fusion hole is usually needed to ensure penetration. The mechanisms and behaviors of fusion hole are different from those of keyholes in other perforation processes. Guo et al. [2] built a low-cost visual detection system for TIG (tungsten inert gas) welding, 
observing the dynamic behaviors of the fusion hole in the front side. They studied the relationship between the shape parameters and the instability of the fusion hole, and built a mathematical analytical model of the characteristic parameters along with the longitudinal instability of the fusion hole. It was found that, when the welding current was $85 \mathrm{~A}$, the fusion hole reached a quasisteady state after growing up, and the ratio of the fusion hole width to gap width fluctuated between 1.8 and 1.9. When the welding current reached $90 \mathrm{~A}$, the ratio of the fusion hole width to gap width increased rapidly and fluctuated between 2.6 and 2.7 in five seconds after the start of welding, due to the accumulation of heat. The fusion hole became unstable and the weld was burnt through. Li et al. [27,28] observed the dynamic behaviors of fusion hole in 304 stainless steel with a thickness of $3 \mathrm{~mm}$, and studied the influences of different welding parameters on the dynamic behaviors of fusion hole. It was found that, with the increase of welding current, the forming time of the fusion hole decreased and the length and width of the fusion hole increased. The ratio of the fusion hole length to width decreased slightly, due to the greater influence of welding current on the increase of fusion hole width. The above research was aimed at the welding of thin plates. Similarly, there are fusion holes in backing welding with reserved gap of the thick plate, but the images of the welding area obtained in thick plate welding are obviously different from those in thin plate welding. Most of the prior prediction models are based on the shape of the molten pool, keyhole and fusion hole to determine the penetration state of the weld. Because of the strong interference of arc radiation, wall reflection and other factors, it is difficult to obtain the morphological characteristics of the molten pool and fusion hole accurately all the time and the image processing process is complex.

In the backing welding process of the thickness plate, it was found that the arc shape changes obviously along with the perforation of the fusion hole. The arc edge in the fusion hole image is clearer than the molten pool and fusion hole edge. In this paper, a passive visual detection method is used to collect the fusion hole images in TIG welding, and an image processing algorithm is designed by the MATLAB commercial software to obtain the arc characteristic parameters of fusion hole images. Taking the arc characteristic parameters as the model input, a prediction model for the penetration process of TIG welding is built. The different states of weld are shown in Figure 1. The perforation states of fusion hole which represents the penetration of weld are classified by SVM (support vector machine). This paper lays a foundation for penetration control of an automatic backing welding process for thick plate.

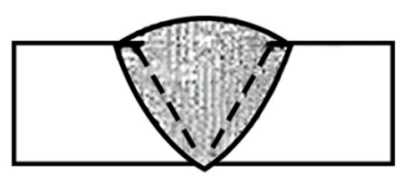

(a)

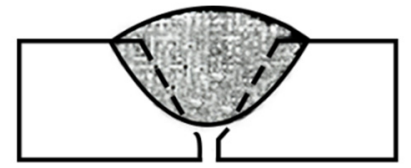

(b)

Figure 1. Two states of the weld: (a) penetration state of weld; (b) nonpenetration state of weld.

\section{Experimental Details}

\subsection{Visual Sensing System Design}

The overall scheme of the TIG welding experimental platform is shown in Figure 2. The experimental platform was mainly composed of a TIG welding machine, a water-cooled welding torch, a wire feeder, two CMOS (complementary metal oxide semiconductor) cameras, a control unit, and a data acquisition card. The control unit was used to regulate the welding speed and the wire feed rate, as well as other welding parameters. 


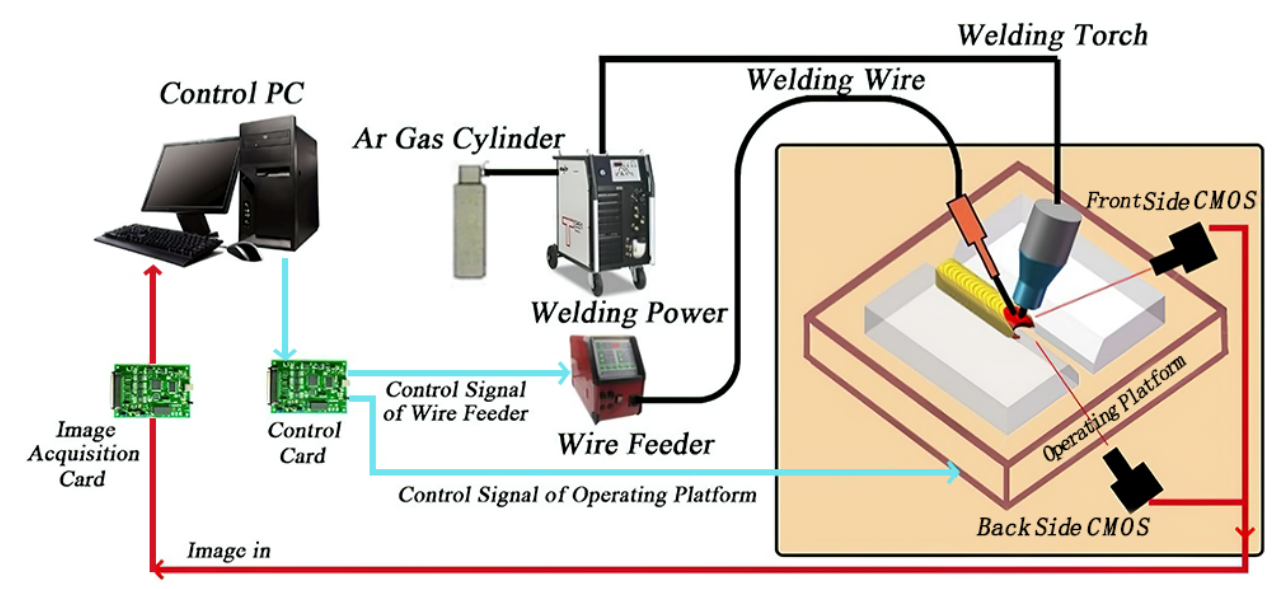

Figure 2. Tungsten inert gas (TIG) welding experimental platform.

Camera 1 was fixed with the welding torch and the tungsten electrode is in the center view of camera 1. Camera 2 was fixed by a tripod. The relative position of the two cameras is shown in Figure 3. Camera 1 was equipped with a narrow-band filter with a central wavelength of $1064 \mathrm{~nm}$, while camera 2 had a narrow-band filter with a central wavelength of $610 \mathrm{~nm}$. The acquisition of front and back arc information was calibrated with the two central wavelength through testing. The two filters' bandwidth was $30 \mathrm{~nm}$ and cutoff depth was OD4(optical density 4).

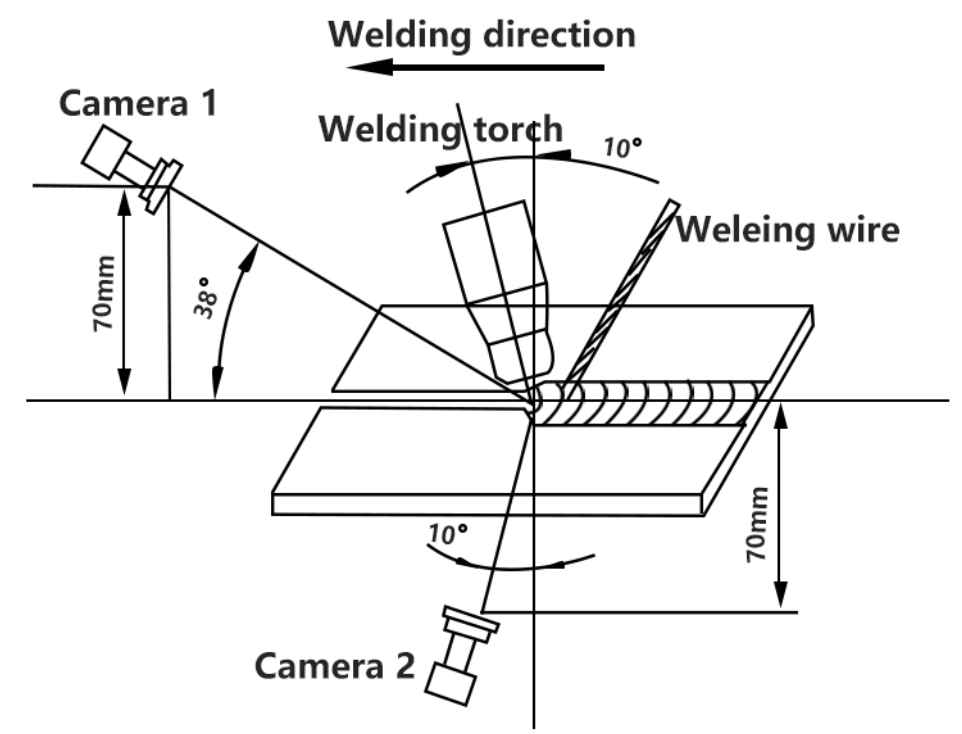

Figure 3. Camera position.

\subsection{Experimental Method}

The material used in this experiment was Q235 steel plate with the size shown in Figure 4. The welding wire was fed from the rear of the molten pool. The welding conditions were as follows: the tungsten electrode diameter was $3.0 \mathrm{~mm}$, the shielding gas was argon (purity 99.99\%), the gas flow rate was set to $15 \mathrm{~L} / \mathrm{min}$, the arc length was $3 \mathrm{~mm}$, and the gap reserved was $2 \mathrm{~mm}$. Tack welding was used at both ends of the test plate in advance to ensure that the reserved gap was constant. The welding parameters are shown in Table 1. 


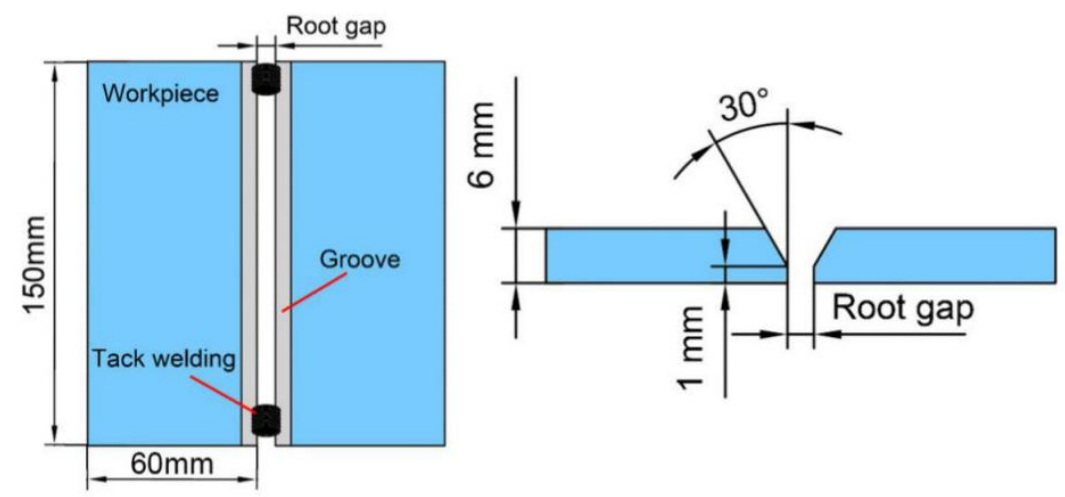

Figure 4. Size of the test plate.

Table 1. Welding parameters.

\begin{tabular}{cccc}
\hline $\begin{array}{c}\text { Test Case } \\
\text { No. }\end{array}$ & $\begin{array}{c}\text { Welding Current } \\
\text { (A) }\end{array}$ & $\begin{array}{c}\text { Welding Speed } \\
(\mathbf{m m} / \mathbf{m i n})\end{array}$ & $\begin{array}{c}\text { Wire Feeding Speed } \\
(\mathbf{m m} / \mathbf{m i n})\end{array}$ \\
\hline CD1-2-3 & $120-130-140$ & 100 & 95 \\
CS1-2-3 & 120 & 100 & $85-95-105$ \\
CJ1 & 120 & 100 & 95 \\
BSD-1 & 120 & $100-120$ & 85 \\
BSD-2 & 120 & $100-80$ & 85 \\
BSS-1 & 120 & 100 & $95-135-95$ \\
\hline
\end{tabular}

\subsection{Visual Sensing System Design}

In this paper, a pinhole model was selected to calibrate CMOS cameras without considering the error caused by lens distortion, which affects the accuracy little and could be neglected. A group of concentric circles with an adjacent distance of $2 \mathrm{~mm}$ was used as the calibration target.

The $x$-axis was perpendicular to the direction of welding, and the $y$-axis was parallel to the direction of welding. $K_{x}$ and $K_{y}$ represent the calibration coefficients of camera 1 on $x$-axis and $y$-axis respectively, and the calibration results were:

$$
\begin{aligned}
& K_{\mathrm{x}}=0.01482 \\
& K_{y}=0.02352
\end{aligned}
$$

\section{Test Data Acquisition}

\subsection{Label of Fusion Hole State}

With the welding speed at $100 \mathrm{~mm} / \mathrm{min}$, the welding current at $140 \mathrm{~A}$ and the wire feed rate at $95 \mathrm{~cm} / \mathrm{min}$, a typical perforation process of fusion hole was obtained and is shown in Figure 5.

After a striking arc in the area of tack welding, the base metal and filler metal in the area were melted under the action of arc heat input. As the welding process continued, the liquid metal in the tack welding area entered the reserved gap, the thickness of the molten pool becomes thinner, and the front end of the molten pool became crescent shaped. The arc acted directly on the front surface of the molten pool, making the temperature of this area higher than that of the surrounding area, and the surface tension in the front end of the molten pool decreased. Under the coupling effect of arc pressure, arc heat and surface tension of molten pool, the crescent shaped liquid in the front end of the molten pool was forced to move backward, forming a semiopen hole- the fusion hole. At $8.97 \mathrm{~s}$, the fusion hole was perforated, as shown in the circle in Figure $5 b$.

The arc area in the circle shown in Figure 5a changed obviously before and after fusion hole perforation. With the increase of fusion hole size, the arc became more concentrated and the area 
which the arc goes through increased. Therefore, the arc area inside the fusion hole could reflect the characteristic information of fusion hole perforation.

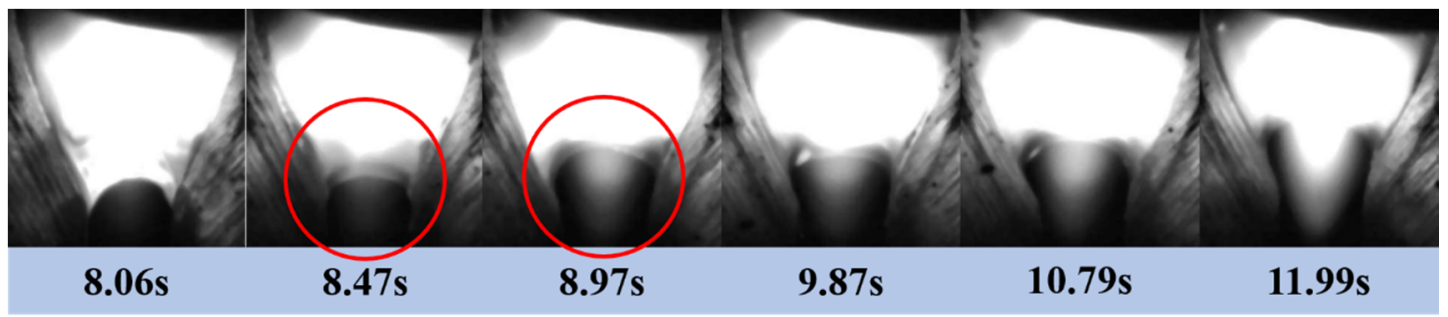

(a)

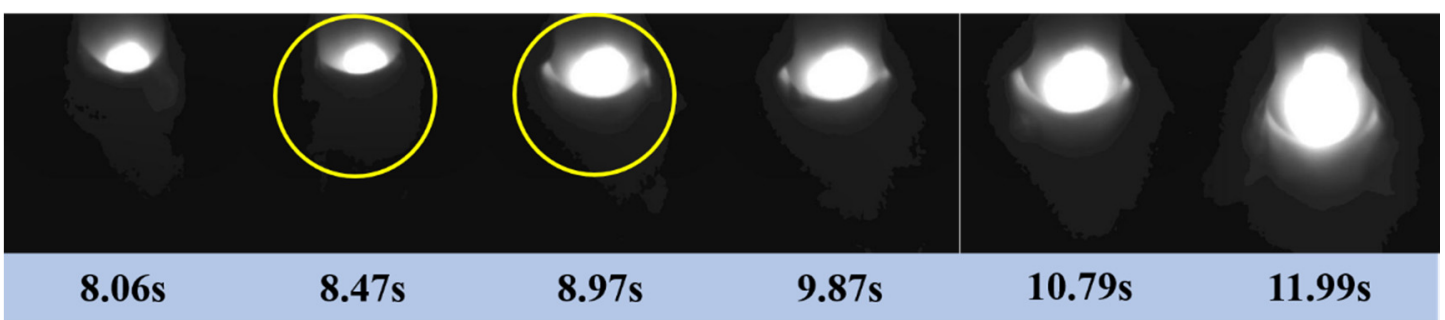

(b)

Figure 5. Typical perforation process of fusion hole: (a) The front images of fusion hole; (b)The backside images of fusion hole.

In this paper, the images of the whole welding process are labeled artificially. The non perforation image is labeled as false, which is a negative sample, and the value is 0 ; the perforation image is labeled as true, which is a positive sample, and the value is 1.

\subsection{Image Processing}

In order to ensure that the weld was penetrated, the fusion hole had to be throughout the work-piece ideally. Figure 6 shows the front image of fusion hole taken by camera 1 .

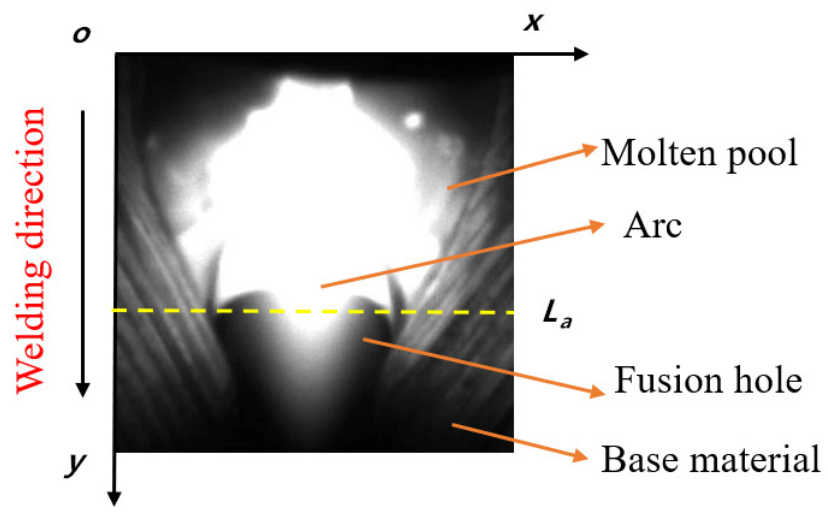

Figure 6. Image of fusion hole in the front side.

In the welding process, the arc light which wasn't reflected to the visual sensor passed through the area of fusion hole and reserved gap, then entered the back side. The arc itself emitted light, so most of the area of the fusion hole and reserved gap was black or gray, and the arc area was bright. The gray scale of line La is extracted in Figure 6 and displayed in Figure 7. The area with a high value of gray scale is the arc center; due to the radiation effect of arc, the further away from the arc center the area is, 
the lower the gray scale value is. The first minimum points $a$ and $b$ appear on both sides of the center line, and the area between $\mathrm{a}$ and $\mathrm{b}$ is taken as the arc area.

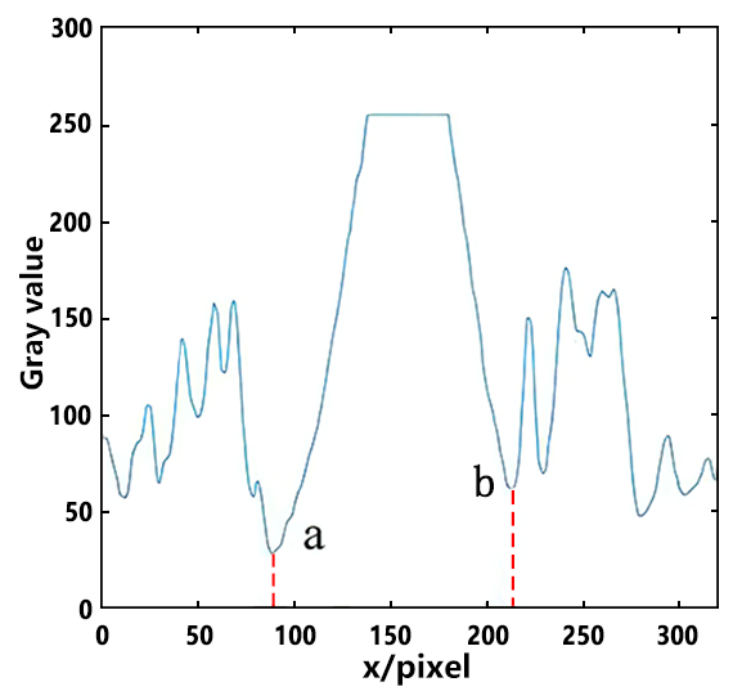

Figure 7. Gray scale distribution in La line.

A fixed size window was used to process the images of the arc area. Only part of the arc area is contained in the window shown in Figure 8a, which is the region of interest. The region of interest in red box is intercepted with the size of $100 \times 320$ pixel, which contains the characteristic information of the arc that must be extracted. The OTSU [29] method was used for threshold segmentation. The image processed by the OTSU method is shown in Figure 8b, and the contour of the front end of the arc is clear.

(a)

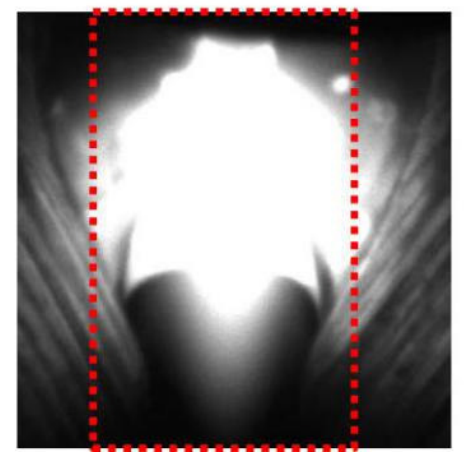

(b)
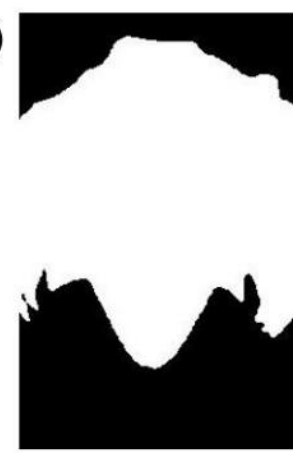

Figure 8. Arc contour obtained by OTSU method: (a) region of interest; (b) threshold segmentation.

When extracting the edge of arc area, the position relationship between the arc and the fusion hole must be considered. Part of the arc travels through the fusion hole when the fusion hole forms, and the front end of the arc is parabolic. The steps of the edge detection algorithm were as follows: (1) a canny [30] edge detection operator was used to detect the edge, and the design algorithm only extracted the lower edge of the arc contour, as shown in Figure 9a; (2) a method based on minimum value was used to remove the extra arc edge and the edge was in the shape of a "parabola", as shown in Figure 9b. It can be seen from Figure $9 \mathrm{c}$ that the edge was well matched. Figure 10 shows the result of image processing without the fusion hole and the edge was almost straight. It can be seen from Figures 9 and 10 that there was a big difference between the arc edges with and without fusion holes. 
(a)

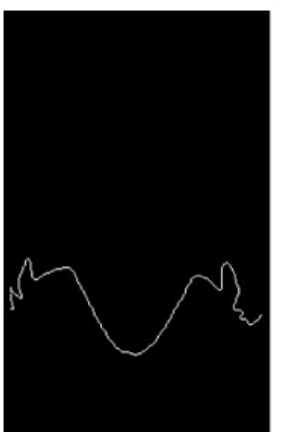

(b)

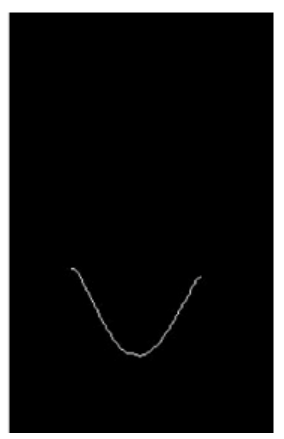

(c)

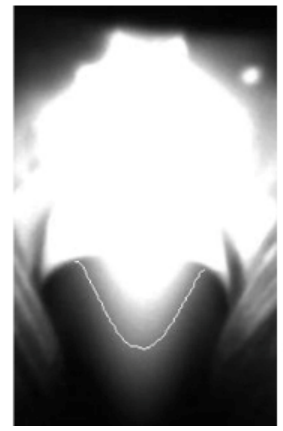

Figure 9. Processing results with fusion hole: (a) canny operator; (b) extra arc edge removed; (c) edge in image.

(a)

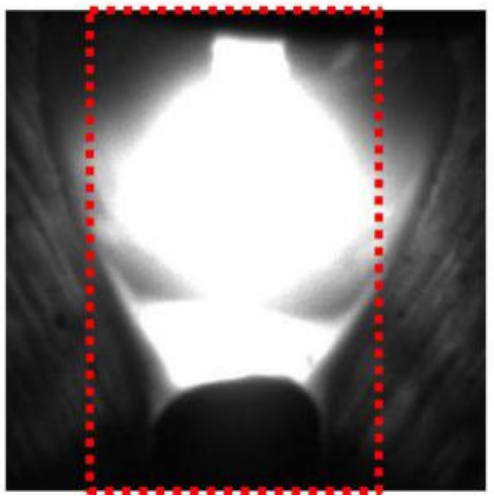

(b)

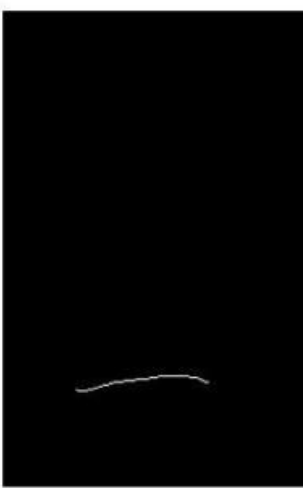

Figure 10. Processing result without fusion hole: (a) canny operator; (b) extra arc edge remove.

\subsection{Characteristic Parameters Extracting}

The typical morphological characteristics of the front end of the arc were defined when the fusion hole exists, as shown in Figure 11. The defined characteristics included the front end width of $\operatorname{arc}\left(W_{1}\right)$, the front end length of arc $\left(L_{1}\right)$ and the width/length ratio of edge curve $(W / L)$. The width/length ratio of the edge curve was equal to the width/length ratio of the minimum circumscribed rectangle of the edge curve.

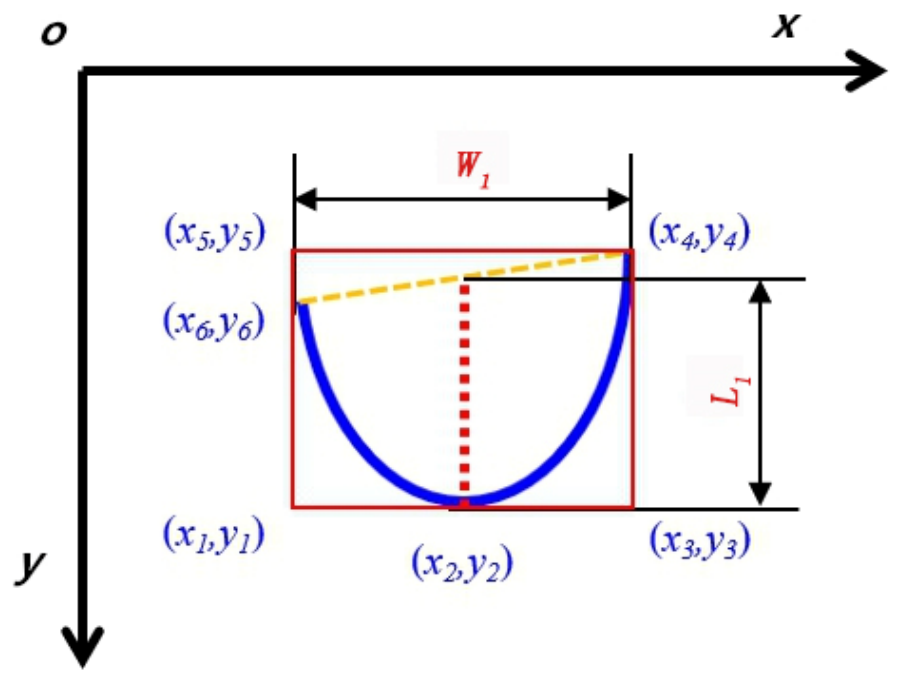

Figure 11. Characteristic image of the arc front end. 
The image was searched line by line from $y=1$ to $y=n$ along the $x$ direction. The coordinates of the outermost points on the left and right sides of the curve are $\left(x_{6}, y_{6}\right)$ and $\left(x_{4}, y_{4}\right)$ respectively. The calculation formula of the arc front end width $\left(W_{1}\right)$ is as follows:

$$
W_{1}=K_{x}\left(x_{6}-x_{4}\right),
$$

Then the image was searched line by line along the $y$ direction and the lowest point $\left(x_{2}, y_{2}\right)$ of edge curve was acquired. The calculation formula of arc front end length $\left(L_{1}\right)$ is as follows:

$$
L_{1}=K_{y}\left[\left(y_{6}-y_{2}\right)+\left(y_{4}-y_{2}\right)\right] / 2,
$$

The width/length ratio $(W / L)$ :

$$
W / L=K_{x}\left(x_{5}-x_{4}\right) /\left[K_{y}\left(y_{5}-y_{1}\right)\right],
$$

The relationships between the points in Figure 11 are as follows: point $\left(x_{5}, y_{5}\right)$ and point $\left(x_{4}, y_{4}\right)$ are on the identical line, which is parallel to $x$-axis; point $\left(x_{1}, y_{1}\right)$, point $\left(x_{2}, y_{2}\right)$ and point $\left(x_{3}, y_{3}\right)$ are on the identical line, which is parallel to the $x$-axis; point $\left(x_{1}, y_{1}\right)$, point $\left(x_{6}, y_{6}\right)$ and point $\left(x_{5}, y_{5}\right)$ are on the identical line, which is parallel to $y$-axis; point $\left(x_{3}, y_{3}\right)$ and point $\left(x_{4}, y_{4}\right)$ are on the identical line, which is parallel to the $y$-axis.

Since the curve of the arc front end with fusion hole is approximately parabolic, the parabola approximation algorithm was used to fit the curve, and the pixel coordinates are recorded as follows:

$$
\left\{\left(\mathrm{x}_{j}, y_{j}\right)\right\}\{j=0,1,2 \ldots n\},
$$

Fit function $t\left(x_{j}\right)$ :

$$
t\left(x_{j}\right)=a x_{j}^{2}+b x_{j}+c,
$$

The coefficients $a, b$ and $c$ are the fitting coefficients.

The sum of square errors is:

$$
E^{2}=\left(\sum\left[t\left(x_{j}\right)-y_{j}\right]^{2}\right),
$$

In the parabolic curve model, the fitting coefficient can represent the characteristics of the parabola. In this paper, the coefficients $(a, b, c)$ of fitting function are taken as the characteristic parameters.

About 250 different fusion hole images were extracted from each experiment. In all the image samples, 2000 images were selected as training samples and 300 images were selected at welding current of $130 \mathrm{~A}$ as the prediction samples. There was no overlap between training samples and the prediction samples. Figure 12 shows the characteristic parameters of training samples. It can be found that the positive and the negative samples can be clearly distinguished by the characteristic parameters. 

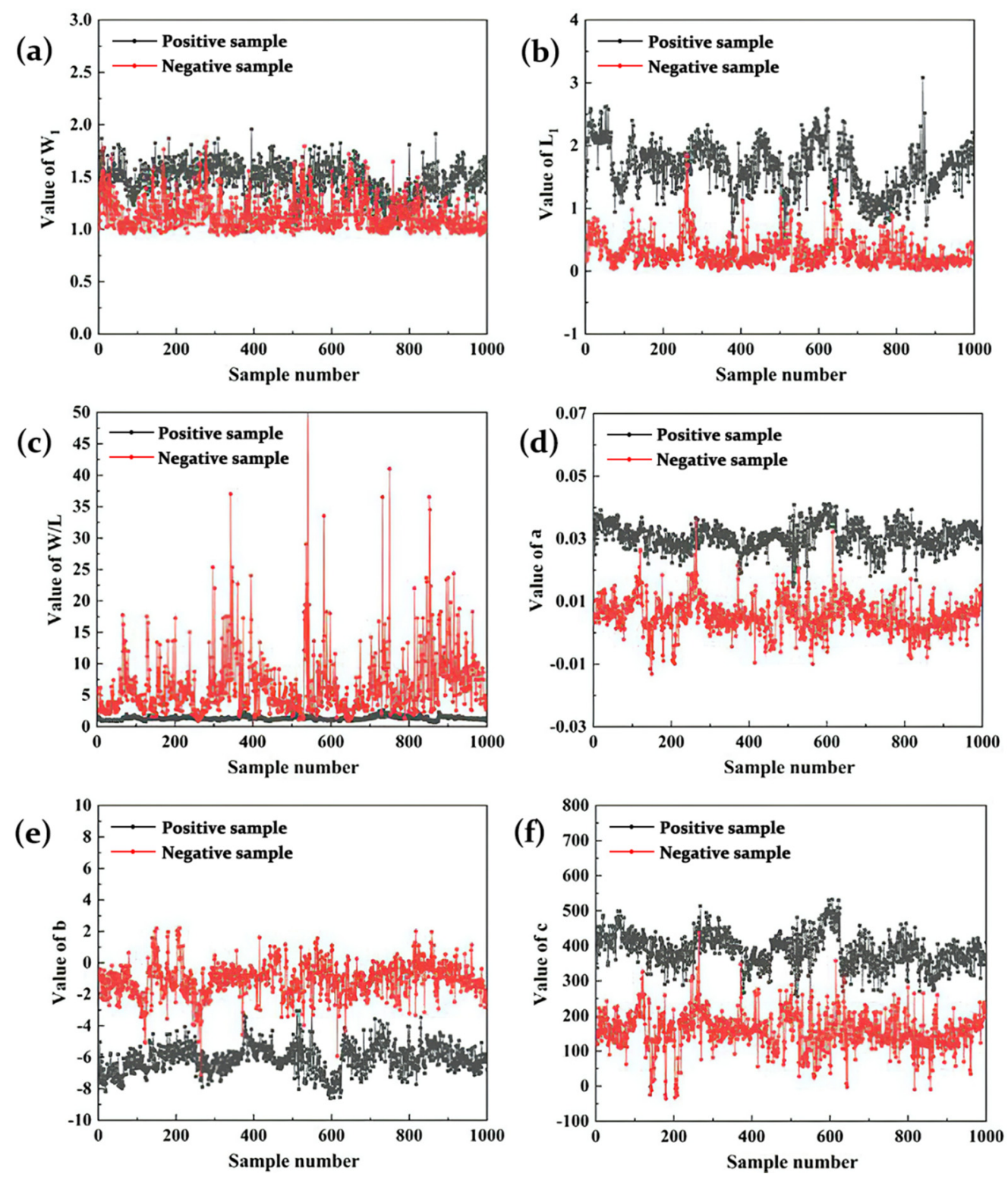

Figure 12. Experimental data of training samples: (a) $W_{1} ;(\mathbf{b}) L_{1} ;$ (c) $W / L ;(\mathbf{d}) a ;(\mathbf{e}) b ;(\mathbf{f}) c$.

\section{Results and Discussion}

\subsection{Fusion Hole Classification Model}

In this paper, the SVM classification method integrating with the image processing technology was used to predict the perforation process of fusion hole. The basic idea of this model was to map the sample data to high-dimensional space through nonlinear mapping, and transform it into a linear separable problem.

The modeling processes of SVM prediction model were as follows:

(1) Based on the training data obtained, the cross validation and the grid-search method were used to find the optimal kernel function $g$ and the penalty function $c$.

(2) The SVM was trained with the training data to obtain the support vector and the model structure was determined.

(3) The model was used to predict the prediction samples.

Grid-searching results of training parameters are shown in Figure 13. The highest accuracy was $99 \%$, and most of the accuracy was higher than $90 \%$, proving that there exists arc characteristic 
parameters which can represent the characteristics of fusion hole perforation. When the accuracy of the test set was highest, the corresponding $\log _{2} c$ and $\log _{2} g$ were taken to obtain the penalty function $c$ and the kernel function $g$. In this paper, $\log _{2} c=0$ and $\log _{2} g=0$ were chosen, and $c$ and $g$ were both equal to 1.

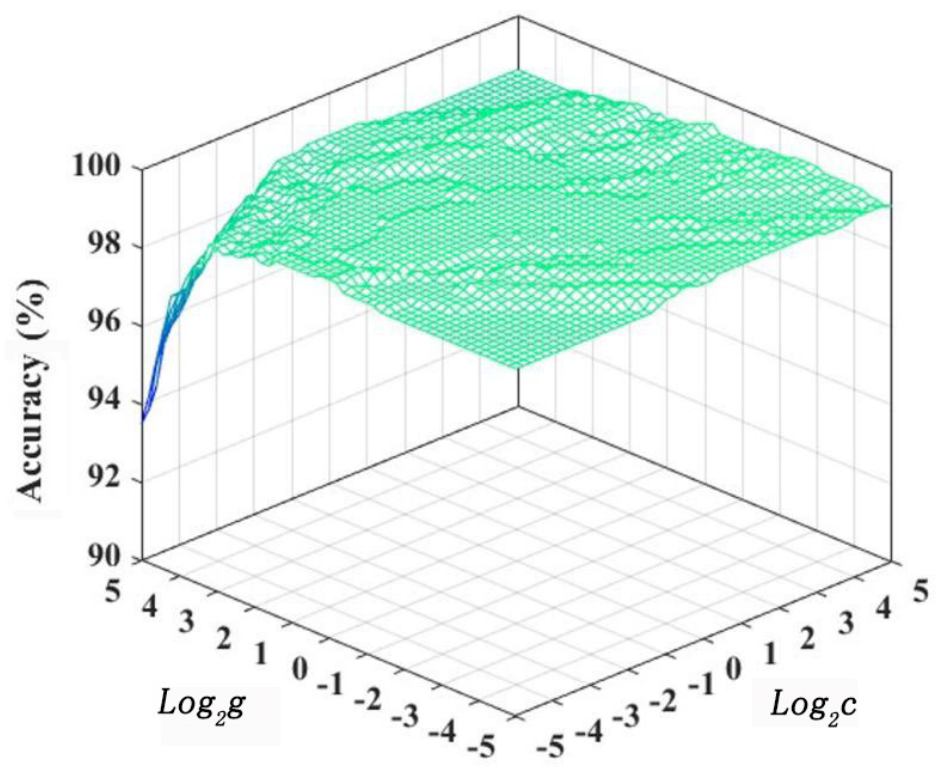

Figure 13. Grid-searching result of training parameters.

\subsection{Prediction of Fusion Hole Formation Based on SVM}

In the field of machine learning, parameters such as accuracy (Acc), precision (P), recall and F1-measure are often used to measure the performance of classifiers. The specific formulas are based on the parameters in Table 2. The calculation method of each formula is shown in Table 3.

Table 2. Statistical parameters of prediction result and actual result.

\begin{tabular}{ccc}
\hline \multirow{2}{*}{ Actual Result } & \multicolumn{2}{c}{ Prediction Result } \\
\cline { 2 - 3 } & Positive & Negative \\
\hline Positive & True Positive (TP) & False Negative (FN) \\
Negative & False Positive (FP) & True Negative (TN) \\
\hline
\end{tabular}

Table 3. Calculation method of formula

\begin{tabular}{ccccc}
\hline Category & Accuracy & Precision & Recall & F $_{\mathbf{1}}$-Measure \\
\hline Formula & $\mathrm{Acc}=\frac{\mathrm{TP}+\mathrm{TN}}{\text { total }}$ & $\mathrm{P}=\frac{\mathrm{TP}}{\mathrm{TP}+\mathrm{FP}}$ & $\mathrm{R}=\frac{\mathrm{TP}}{\mathrm{TP}+\mathrm{FN}}$ & $\mathrm{F}_{1}=\frac{2 \times \mathrm{P} \times \mathrm{R}}{\mathrm{P}+\mathrm{R}}$ \\
\hline
\end{tabular}

The weld was not always penetrated when the fusion hole did not perforate. When the model predicts nonperforation as perforation, the system will misjudge that the weld has penetrated at this time, which has a vital impact on the weld forming quality. Therefore, the number of negative samples misjudged by the model as positive ones must be strictly controlled, and even equal 0 . When the model predicted the perforation samples as nonperforation ones, the weld is penetrated, which had little effect on the model. If there was little difference in accuracy, the higher the P was, the better the predict result was.

The prediction results are shown in Figure 14 and Table 4. According to the data, the critical point from nonperforation to perforation was defined as the perforation limit. 


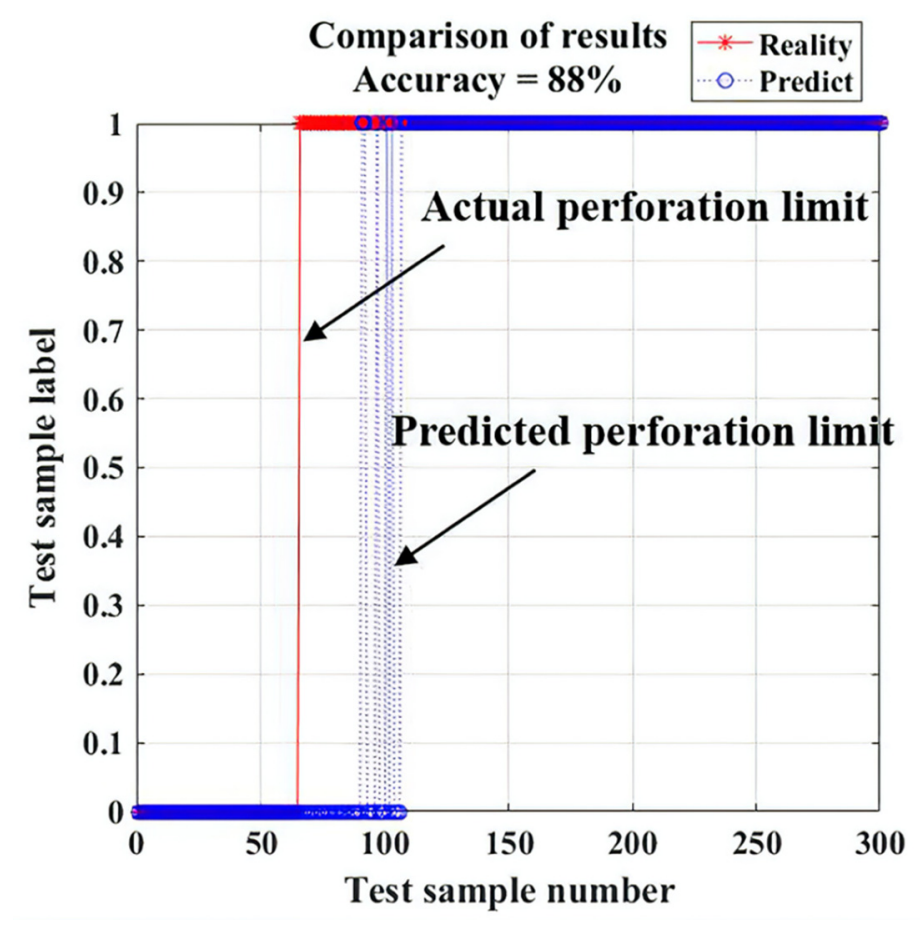

Figure 14. Experimental result.

Table 4. Experimental result.

\begin{tabular}{ccccc}
\hline Category & Accuracy & Precision & Recall & F $_{\mathbf{1}}$-Measure \\
\hline Value-SVM & $88.00 \%$ & $100.00 \%$ & $84.68 \%$ & $91.70 \%$ \\
\hline
\end{tabular}

The experimental result shows that the Acc and the F1-Measure were slightly above or below $90 \%$ and the precision was 100\%, which means that the prediction model had a strong detection ability for positive samples, and it was difficult to predict the images of nonperforation as the ones of perforation. For the images of perforation, the true accuracy was $84.68 \%$, and there were no misidentified samples after the predicted perforation limit, which proves that the characteristic parameters of arc can obviously characterize the perforation and can effectively be selected to predict perforation.

The experimental data of prediction samples are shown in Figure 15. In the nonperforation stage, the characteristic parameters of the arc tended to be steady. In the period between actual perforation and predicted perforation limit, $W_{1}, L_{1}, a$ and $c$ increased constantly, while $W / L$ and $b$ decreased. After the predicted perforation limit, the characteristic parameters of the arc tended to be steady again. The characteristic parameters of the arc in the nonperforation stage were different from those in the stage after predicted perforation limit, and the two sets of parameters were stratified obviously, which proves that the characteristic parameters of the arc can obviously characterize the perforation again. The misjudged samples were concentrated in the initial stage of perforation, and Figure 16 shows the misidentified images. As the fusion hole was just perforated, the arc inside the arc area was weak. Although all the characteristic parameters of the arc changed, there was no obvious difference of the parameters' values in this stage compared with the nonperforation stage. With the increase of fusion hole size, the arc characteristic parameters all changed obviously, and then tended to be stable. 

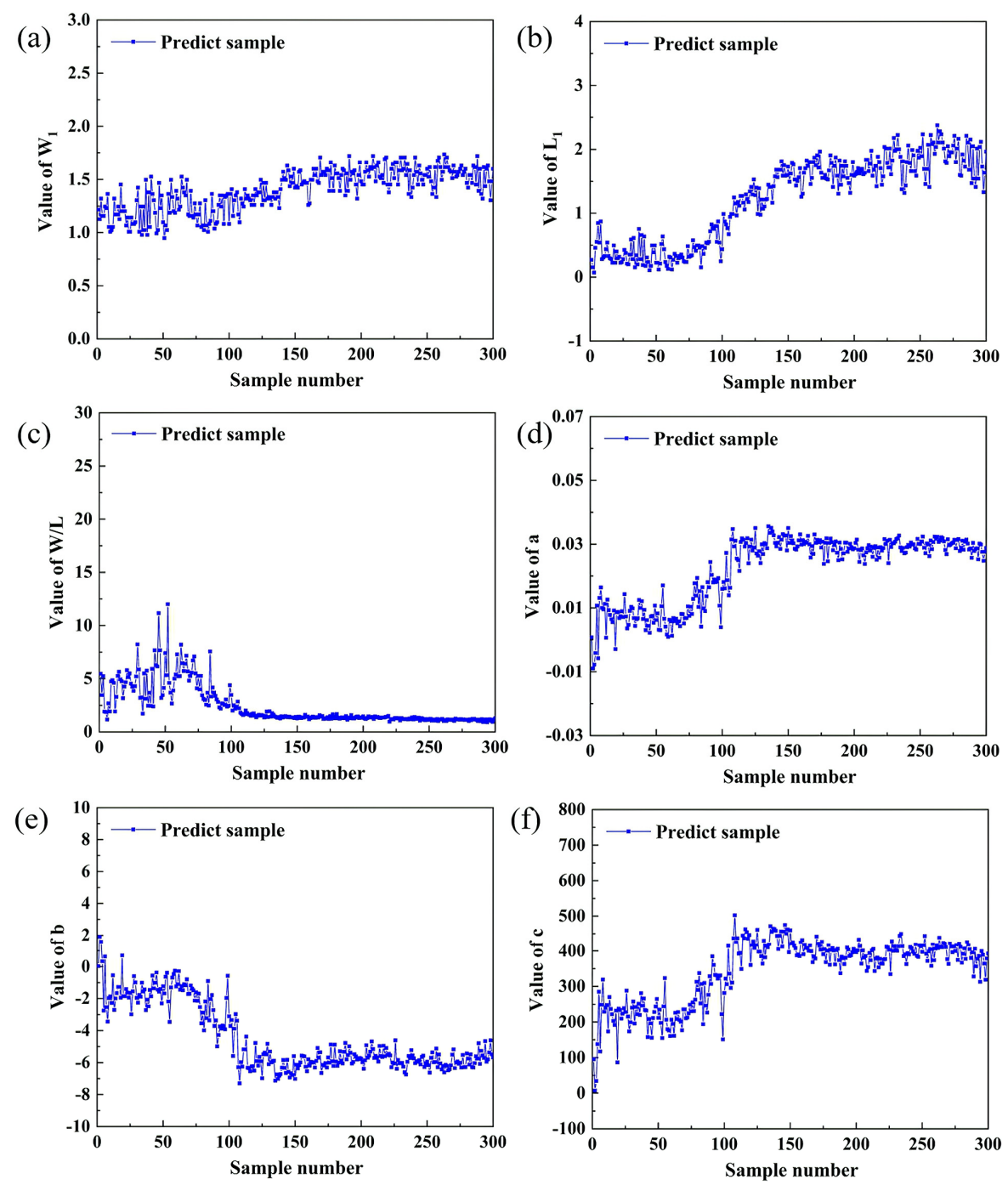

Figure 15. Experimental data of prediction samples: (a) $W_{1} ;(\mathbf{b}) L_{1} ;$ (c) $W / L ;$ (d) $a ;(\mathbf{e}) b ;(\mathbf{f}) c$.
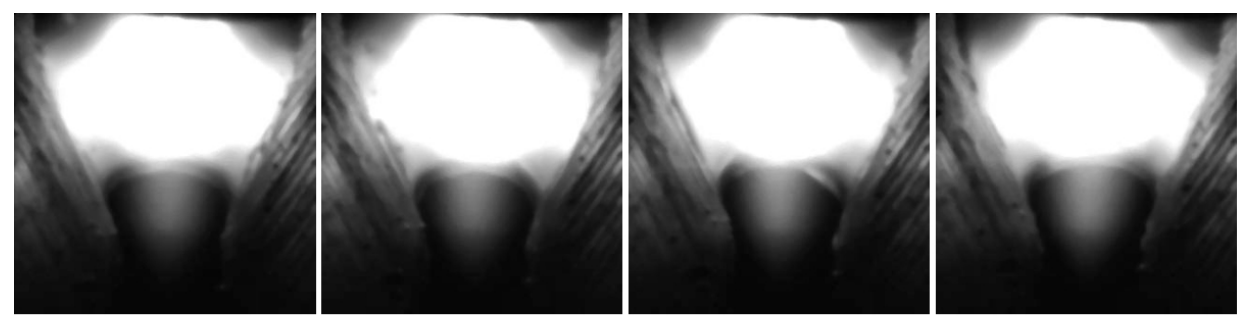

Number $=70$

Number $=75$

Predict $=0$

Number $=80$

Predict $=0$

Number $=85$
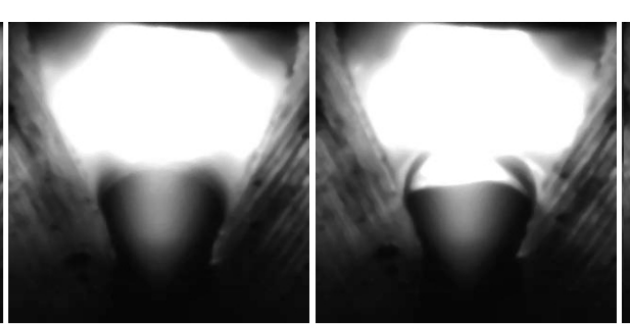

Predict $=0$

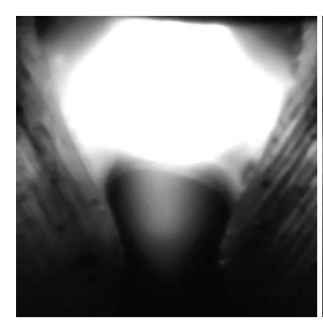

Figure 16. Misidentified images. 
After stable perforation, the perforation state could be easily identified. The predicted perforation limit time was $0.8 \mathrm{~s}$ later than the actual time, and there were about 40 images in this period. When the fusion hole perforation state was given by the model, the fusion hole already had a certain size, which ensured the weld was penetrated.

\section{Conclusions}

(1) A visual detection system of a fusion hole in TIG backing welding was built, and clear images of the front and the back fusion hole were obtained.

(2) With the increase of fusion hole size, the arc gradually passed through the fusion hole, and there were obvious differences between the arc before and after fusion hole perforation. The arc characteristics of front fusion hole images could be used as the basis for judging the state of the fusion hole.

(3) The image processing method was designed and the arc characteristic parameters were obtained.

(4) Taking arc characteristic parameters as the model input, penalty function and kernel function parameters were obtained by cross validation and grid-search method. A prediction model of fusion hole perforation in TIG welding based on SVM was constructed. The results show that the classification accuracy of the model reached $88 \%$, and the time of prediction perforation limit was slightly later than the actual one, which was conducive with ensuring the weld penetration.

Author Contributions: Conceptualization, J.G., Y.C. and C.J.; methodology, J.G., Y.C. and C.J.; formal analysis, X.W.; investigation, X.Y.; resources, X.Y.; writing—original draft preparation, Y.C.; writing—review and editing, X.W.; supervision, J.G. and C.J.; project administration, J.G.; funding acquisition, J.G. All authors have read and agreed to the published version of the manuscript.

Funding: This research was funded by National Natural Science Foundation of China, grant number 51675309.

Conflicts of Interest: The authors declare no conflict of interest

\section{References}

1. Cai, C.Y. Technology and technique of one-side welding with back-formation. Weld. Technol. 2016, 45, 92-94.

2. Guo, Y.J.; Gao, J.Q.; Wu, C.S.; Gui, X. Correlation between fusion hole morphology and weld penetration in TIG welding. Int. J. Adv. Manuf. Technol. 2019, 101, 2991-3000. [CrossRef]

3. Shi, Y.; Wang, K.F.; Zhang, G.; Zhu, Y.R. Arc Shape and Weld Pool Behavior in Low-frequency Pulse TIG Backing Welding for Medium and Thick Plates. J. South Chi. Univ. Technol. 2019, 47, 107-113.

4. Saad, E.; Wang, H.; Kovacevic, R. Classification of molten pool modes in variable polarity plasma arc welding based on acoustic signature. J. Mater. Process. Technol. 2006, 174, 127-136. [CrossRef]

5. Dong, C.L.; Wu, L. Front side keyhole detection in plasma arc welding of stainless steel. Chi. Weld. 1999, 8, 102-110.

6. Drouet, M.G.; Nadeau, F. Acoustic mesurement of the arc voltage applicable to arc-welding and arc furnaces. J. Phys. E-Sci. Instrum. 1982, 15, 268-269. [CrossRef]

7. Chen, C.; Xiao, R.Q.; Chen, H.B.; Lv, N.; Chen, S. Arc sound model for pulsed GTAW and recognition of different penetration states. Int. J. Adv. Manuf. Technol. 2020, 108, 3175-3191. [CrossRef]

8. Jia, C.-B.; Wu, C.; Zhang, Y.-M. Sensing controlled pulse key-holing condition in plasma arc welding. Trans. Nonferrous Met. Soc. China 2009, 19, 341-346. [CrossRef]

9. Liu, X.F.; Wu, C.S.; Jia, C.B.; Zhang, G. Visual sensing of the weld pool geometry from the topside view in keyhole plasma arc welding. J. Manuf. Process. 2017, 26, 74-83. [CrossRef]

10. Wang, H.; Kovacevic, R. On-line monitoring of the keyhole welding pool in variable polarity plasma arc welding. Proc. Inst. Mech. Eng. Part B J. Eng. Manuf. 2002, 216, 1265-1276. [CrossRef]

11. Bae, K.-Y.; Lee, T.-H.; Ahn, K.-C. An optical sensing system for seam tracking and weld pool control in gas metal arc welding of steel pipe. J. Mater. Process. Technol. 2002, 120, 458-465. [CrossRef]

12. Bacioiu, D.; Melton, G.; Papaelias, M.; Shaw, R. Automated defect classification of SS304 TIG welding process using visible spectrum camera and machine learning. NDTEE INT. 2019, 107, 102139. [CrossRef] 
13. Zhang, B.; Shi, Y.; Cui, Y.; Wang, Z.; Hong, X. Prediction of keyhole TIG weld penetration based on high-dynamic range imaging. J. Manuf. Process. 2020, in press. [CrossRef]

14. Zhang, G.; Wu, C.; Liu, Z. Experimental observation of both keyhole and its surrounding thermal field in plasma arc welding. Int. J. Heat Mass Transf. 2014, 70, 439-448. [CrossRef]

15. Zhang, G.; Wu, C.; Chen, J. Single CCD-based sensing of both keyhole exit and weld pool in controlled-pulse PAW. Weld. World 2018, 62, 377-383. [CrossRef]

16. Liu, Z.; Chen, S.; Liu, S.; Luo, Z.; Yuan, J. Keyhole dynamic thermal behaviour in K-TIG welding process. Int. J. Heat Mass Transf. 2018, 123, 54-66. [CrossRef]

17. Liu, Z.; Chen, S.; Yuan, X.; Zuo, A.; Zhang, T.; Luo, Z. Magnetic-enhanced keyhole TIG welding process. Int. J. Adv. Manuf. Technol. 2018, 99, 275-285. [CrossRef]

18. Liu, Z.M.; Fang, Y.X.; Cui, S.L.; Luo, Z.; Liu, W.; Liu, Z.; Jiang, Q.; Yi, S. Stable keyhole welding process with K-TIG. J. Mater. Process. Technol. 2016, 238, 65-72. [CrossRef]

19. Luo, M.; Shin, Y.C. Estimation of keyhole geometry and prediction of welding defects during laser welding based on a vision system and a radial basis function neural network. Int. J. Adv. Manuf. Technol. 2015, 81, 263-276. [CrossRef]

20. Bardin, F.; Cobo, A.; Lopez-Higuera, J.M.; Collin, O.; Aubry, P.; Dubois, T.; Högström, M.; Nylen, P.; Jonsson, P.; Jones, J.D.C.; et al. Closed-loop power and focus control of laser welding for full-penetration monitoring. Appl. Opt. 2005, 44, 13-21. [CrossRef]

21. Wang, X. Three-dimensional vision applications in GTAW process modeling and control. Int. J. Adv. Manuf. Technol. 2015, 80, 1601-1611. [CrossRef]

22. Chen, K.; Chen, H.-B.; Liu, L.; Chen, S. Prediction of weld bead geometry of MAG welding based on XGBoost algorithm. Int. J. Adv. Manuf. Technol. 2018, 101, 2283-2295. [CrossRef]

23. Xia, C.; Pan, Z.; Fei, Z.; Zhang, S.; Li, H. Vision based defects detection for Keyhole TIG welding using deep learning with visual explanation. J. Manuf. Process. 2020, 56, 845-855. [CrossRef]

24. Liu, X.F. Topside Visual Sensing and Deep Learning Algorithm Based Prediction of Keyhole Status/Penetration in Plasma Arc Welding. PhD Thesis, Shandong University, Jinan, China, 2017.

25. Zhang, B.; Gu, S.; Shi, Y. Robotic Deep Penetration K-TIG Welding System Based on Weld Penetration Detection. J. Mech. Eng. 2019, 55, 14-21.

26. Wu, D.; Chen, J.S.; Liu, H.B.; Zhang, P.; Yu, Z.; Chen, H.; Chen, S. Weld penetration in situ prediction from keyhole dynamic behavior under time-varying VPPAW pools via the OS-ELM model. Int. J. Adv. Manuf. Technol. 2019, 104, 3929-3941. [CrossRef]

27. Li, C.Z.; Gao, J.Q.; Cao, Y.; Yan, X.; Gui, X. Visual observation of fusion hole in thin plate TIG welding with a reserved gap. J. Manuf. Process. 2019, 45, 634-641. [CrossRef]

28. Guo, Y.J.; Gao, J.Q.; Cao, Y.; Li, C.; Li, C. Behavior of the Fusion Hole in Tungsten Inert Gas Thin-Plate Welding. IEEE Robot. Autom. Lett. 2019, 4, 2801-2806. [CrossRef]

29. Otsu, N. A Threshold Selection Method from Gray-Level Histograms. IEEE Trans. Syst. Man Cybern. 1979, 9, 62-66. [CrossRef]

30. Canny, J. A Computational Approach to Edge Detection. IEEE Trans. Pattern Anal. Mach. Intell. 1986, 8, 679-698. [CrossRef]

Publisher's Note: MDPI stays neutral with regard to jurisdictional claims in published maps and institutional affiliations.

(C) 2020 by the authors. Licensee MDPI, Basel, Switzerland. This article is an open access article distributed under the terms and conditions of the Creative Commons Attribution (CC BY) license (http://creativecommons.org/licenses/by/4.0/). 